\title{
Author Correction: Bringing back the golden days of Bell Labs
}

\section{Iulia Georgescu}

Correction to: Nature Reviews Physics volume 4, 76-78 (2022) https://doi.org/10.1038/s42254-022-00426-6 published online 27 January 2022.

In the original version of this article, there was a mistake in the sentence "However, AT\&T "maintained its monopoly at the government's pleasure, and with the understanding that its scientific work was in the public's interest" ${ }^{2}$ so it could not patent and commercialize the technology Bell

Labs developed." The text should have read "However, ATET “maintained its monopoly at the government's pleasure, and with the understanding that its scientific work was in the public's interest" so it could not fully exploit the technology Bell Labs developed." This error has now been corrected in the HTML and PDF versions of the article.

https://doi.org/10.1038/s42254-022-00433-7 I Published online 14 February 2022

(c) Springer Nature Limited 2022 